\title{
Psycho-emotional Disability in the Marketplace
}

\begin{abstract}
Purpose: This study, through adoption of the psycho-emotional model of disability, aims to offer consumer research insight into how the marketplace internally oppresses and psychoemotionally disables consumers living with impairment.
\end{abstract}

Design/methodology/approach: This paper draws insight from the interview data of a wider two-year interpretive research study investigating access barriers to marketplaces for consumers living with impairment.

Findings: The overarching contribution offers to consumer research insight into how the marketplace internally oppresses and psycho-emotionally disables consumers living with impairment. Further contributions offered by this paper: i) unearth the emotion of fear to be central to manifestations of psycho-emotional disability, ii) reveal a broader understanding of the marketplace practices, and core perpetrators, that psycho-emotionally disable consumers living with impairment, and iii) uncover psycho-emotional disability to extend beyond the context of impairment.

Originality/value: Extending current consumer research and consumer vulnerability research on disability, the empirical adoption of the psycho-emotional model of disability is a fruitful framework for extrapolating insight into marketplace practices that internally oppress and psycho-emotionally disable consumers living with impairment. 
Practical implications: The insight offered into the precise marketplace practices that disable consumers living with impairment leads this paper to call for a revising of disability training within marketplace and service contexts.

Research limitations/implications: This study adopts a UK-only perspective. However, findings uncovered that the model of psycho-emotional disability has wider theoretical value to marketing and consumer research beyond the context of impairment.

Keywords: Consumer research, consumer vulnerability, exclusion, psycho-emotional model of disability, disability, ableism. 


\section{Introduction}

One in six people in the EU have a disability, approximating to almost 80 million (European Commission, 2020). Around fourteen million people in the UK have a disability, and hold an estimated spending power of around $£ 249$ billion. The UK's failure to appropriately cater to this consumer segment witnesses monthly losses of $£ 163$ million for restaurants, pubs and clubs, $£ 267$ million for high street shops, and a mammoth $£ 501$ million for supermarkets (https://wearepurple.org.uk/the-purple-pound-infographic/). Consequently, despite their economic value, consumers living with impairment ${ }^{1}$ remain under-targeted (Pavia and Mason, 2012, 2014; Echeverri and Salomonson, 2019).

The UN Convention on the Rights of Persons with Disabilities $(2006,4)$ defines disability to "include those who have long-term, physical, mental, intellectual or sensory impairments, which in interaction with various barriers may hinder their full and effective participation in society on an equal basis with others". This definition aligns with what disability theory terms the social model of disability (i.e., Imrie, 1997, Shakespeare, 2004, Reeve, 2012a, 2012b, Goodley, 2017). The social model distinguishes between impairment and disability, perceiving environmental and socio-political structures, not one's medical impairment, as disabling. A strength of the social model is the insight it provides into the "material barriers" and "material inequalities" faced by consumers living with impairment (Goodley 2017, 11). However, the social model does have criticisms, a primary one being that it overlooks the psycho-emotional barriers and psychological inequalities experienced by consumers living with impairment (Thomas, 1999, 2007; Reeve, 2002, 2004, 2012a, 2012b). In response to this limitation, disability theory has moved towards better understanding personal and psychological experiences of impairment, through what is coined the psycho-

\footnotetext{
${ }^{1}$ This paper adopts a people-centred perspective towards disability (Goodley 2017), consequently utilising the term consumers living with impairment over disabled consumers or impaired consumers as a means of prioritising the person over impairment.
} 
emotional model of disability (Thomas, 1999, 2007; Reeve, 2002, 2004, 2012a, 2012b). This model complements and extends the social model, offering understanding of the material and structural barriers of disability (i.e., lack of ramps, disabled parking, etc.), whilst also elucidating how socially normative structures, signs, symbols and practices can internally oppress and psychologically disable consumers living with impairment, rendering them to feel abnormal and inadequate to society.

A growing body of research investigating disability within marketplace and commercial settings has developed since the 1990s (i.e., Kaufman-Scarborough, 1999, 2001; Baker, 2006; Baker et al., 2001, 2002; Mason and Pavia 2006; Pavia and Mason 2012, 2014; Navarro et al., 2014; Beudaert et al., 2016, 2017; Beudaert, 2018; Echeverri and Salomonson, 2019; Kearney et al., 2019). Work in this area has evolved in a similar manner to disability theory, with discourse initially (and at times still) adopting a social model perspective, often prioritising how structural and materials inequalities in retail and service design disable consumers living with impairment (e.g., Kaufman-Scarborough, 1995, Baker et al., 2007, Navarro et al. 2014). However, recent discussions have begun to focus on the personal understandings and lived realities of disability (i.e., Mason and Pavia, 2006; Pavia and Mason, 2012, 2014; Echeverri and Salomonson, 2019). This latter work contributes greatly to consumer vulnerability discourse, exposing consumers living with impairment to feel unwelcome, stigmatized and abnormal, rendering them vulnerable in commercial settings (Mason and Pavia, 2006; Pavia and Mason, 2012). This work has been instrumental in raising awareness of disability exclusion in the marketplace, and sharing how consumers living with impairment attempt to overcome consumer vulnerability through coping and adaptation strategies.

Based on a two-year interpretive research study investigating barriers to marketplace settings for consumers living with impairment, this paper adopts the psycho-emotional model 
of disability (Reeves, 2002, 2004) to advance consumer research on disability. In doing so, this paper offers a renewed interpretation of this latter work, revealing how to date the marketplace has inadvertently perpetuated internalised oppression and psycho-emotional disability by placing responsibility to adapt upon consumers living with impairment, rather than marketplace actors. Thus, this paper offers to consumer research insight into the marketplace practices, interactions and services that internally oppress and psycho-emotionally disable consumers living with impairment, and calls for a repositioning of responsibility upon the marketplace to adapt to meet their needs. Further contributions offered by this paper: i) unearth the emotion of fear to be central to manifestations of psycho-emotional disability, ii) reveal a broader understanding of the marketplace practices, and core perpetrators, that psycho-emotionally disable consumers living with impairment, and iii) uncover psycho-emotional disability to extend beyond the context of impairment.

The paper is organised as follows. Structured around models of disability, the literature section offers insight into consumer research on disability and discusses fully the psychoemotional model of disability (Reeve, 2004). Next, the methodological approach and process is discussed. Findings are organised around the three facets of the psycho-emotional model of disability: structural barriers, social interaction and internalised oppression (Reeve, 2004). Finally, the paper concludes with a discussion section, revealing core contributions, theoretical and practical implications, limitations and future research streams.

\section{Literature Review}

Social Model of Disability

Preceding the social model, the medical model of disability believed medical conditions, not society, to be debilitating to consumers living with impairment, therefore perceiving impairment to be an individual, private matter. Such logic stems from a moral or 
tragic perspective (Oliver, 1990). The former views impairment as punishment from Deity due to individual moral lapse or sin (Snyder and Mitchell, 2001); the latter perceives persons with impairment as in need of fixing and curing, consequently they are "ignored, pitied, patronised, objectified, hated, mocked and fetishized" (Goodley, 2017, 2).

Contrarily, the social model of disability perceives the environment and socio-political structures, not the medical impairment, as disabling (Imrie, 1997; Shakespeare, 2004). Consequently, the social model repositioned the issue of impairment from the individual to the public, providing insight into the environmental and social inequalities subjected upon consumers living with impairment (Goodley, 2017). However, Shakespeare (2004, 13) critiques the social model for breeding an ethos of essentialism, whereby all impairments are perceived to be the same. For example, the signifier for disability - $\dot{k}$ - the wheelchair symbol established in 1968, is a clear example of essentialism whereby disability is conceptually reduced as relating solely to mobility impairment, leading in turn to the building of derogative caricatures (Guffey, 2018) and "unfavourable societal stereotyping" (Hutchinson et al. 2018, 189). Furthermore, as aforementioned, the social model of disability overlooks the psychoemotional barriers and psychological inequalities experienced by consumers living with impairment (Thomas, 2007, Reeve, 2002). Likewise, it fails to recognise that consumers living with impairment can and do live full, satisfying, lives (Swain and French, 2000), but rather assumes that they wish to be able-bodied (Shakespeare, 2004).

This essentialism of impairment and the assumption that consumers living with impairment desire to be able-bodied, stems from ableism. Chouinard (1997, 380) defines ableism as the "ideas, practices, institutions and social relations that presume ablebodiedness, and by doing so construct persons with impairments as marginalised, oppressed and largely invisible 'others"'. The dominance of ableism has resulted in the design of services, architecture and cityscapes for the dominant able-bodied, which in turn, thwarts consumers 
living with impairment from full participation in socio-cultural structures, such as consumer culture. Based on tenants of individualism, ableism has socialised Western society to perceive people who are not fully independent to be "morally inferior", causing those needing assistance to feel ashamed and burdensome (Galvin, 2005, 402-403). Indeed, Imrie (1997, 265) asserts disability discourse to be a "projection of "able-bodied" values which legitimize oppressive and discriminatory practices" against consumers living with impairment. Imrie's $(1997,265)$ assertion calls to mind Denegri-Knott et al.’s $(2006,960)$ discursive power model, concerning discourse strategies that produce dominant socio-cultural constructs, with norms established through "the internalization of an external discourse of normalcy and conduct". Consequently, ableism is a cultural power model, which imposes onto consumers a "specific behavioural and cognitive logic" (Denegri-Knott et al., 2006, 959).

To date, consumer research within the context of disability and impairment has often privileged the social model of disability (e.g. Kaufman-Scarborough, 1999; Yu et al., 2015; Navarro et al., 2014). Primarily, this perspective prioritises how inequalities in retail and service design structurally disable consumers living with impairment, creating inequalities during marketplace encounters. Kaufman-Scarborough $(2015,158)$ asserts that the predominant focus on able-bodied consumers has resulted in a failure to understand impairment within marketplaces and services. For example, in earlier work, Kaufman-Scarborough (1999) outlines how retail spaces such as supermarkets often overlook height-appropriate displays for consumers living with impairment. This is emblematic of retailers taking an essentialist approach, perceiving all impairment as the same. Similarly, Navarro et al. (2014) demonstrate how, in the hotel industry, there remains a distinct lack of adequate service training to cater for consumers living with impairment. They illustrate a common trait of hotels is a lack of precise online information regarding disability access. Additionally, Yu et al. (2015) uncover retail and service design to be disabling to consumers with visual impairment, with bright lighting, 
signage colour and font proving problematic. These studies demonstrate how the marketplace caters to regulations established in acts such as the American Disability Act and the UK Equality Act, yet oftentimes fail to meet the actual needs of those living with impairment. While useful in demonstrating how retail and service design structurally disable consumers living with impairment, this perspective has overlooked the realities of their lived experiences. In response to this, a body of consumer research has emerged (i.e., Baker, 2006; Mason and Pavia, 2006; Pavia and Mason, 2012, 2014; Beudaert et al., 2016, 2017; Beudaert, 2018; Echeverri and Salomonson, 2019), offering more personal understandings of the lived realities of impairment and disability.

\section{Personal Understandings of Impairment within Consumer Research}

Baker $(2006,47)$ outlines a negative consequence of marketing segmentation is its othering of, and projection of abnormality onto consumers who differ from dominant discourses of normalcy. Consumer normalcy is achieved when one is able to enact their consumer identity whilst co-existing with other consumers within marketplace settings, and is believed to be crucial in the building and stabilising of one's sense of self (Baker, 2006). Indeed, as Trees and Dean (2018) outline, in their investigation of cognitive impairment caused by dementia, the routine of shopping can be instrumental in sustaining a sense of self. Others have also highlighted how feelings of abnormality and loss of stability within marketplace settings can result in consumers feeling "flawed" (Bauman, 2005, 38) and an "[un]natural part of the marketplace" (Baker, 2006, 39).

A large proportion of consumer research contributing towards personal understandings of impairment focusses upon the coping and adaptation strategies developed and enacted by consumers living with impairment during marketplace encounters (i.e., Mason and Pavia, 2006; Pavia and Mason, 2012; Elms and Tinson, 2012; Beudaert et al., 2017; Echeverri and 
Salomonson, 2019). For example, Pavia and Mason (2012) uncover parents of children with impairment often feel the need to make difficult decisions on whether to consume as subgroups that either include or exclude the family member with impairment. They note that instances of exclusion are often predicated on families' attempts to avoid the stigma of "being the sort of consumer that thinks it is acceptable to bring congestion, bulk, delays" to the marketplace (Pavia and Mason, 2012, 105). Equally and ironically, instances of inclusion often witness parents devising "escape plans", permitting quick escape from commercial settings when and if impairment disrupts consumption norms (i.e., a child with autism or behavioural impairment acting out). The devising of such escape plans is indicative of how parents to children with impairment feel their children, and themselves by association, are an "[un]natural part of the marketplace" (Baker, 2006, 39). Echeverri and Salomonson (2019) uncover the similar implementation of proactive coping strategies by consumers living with impairment during in-situ service interactions. For example, directly communicating their impairment needs to service providers prior to the service encounter was a means of alleviating potential challenges. Both studies outline coping strategies help consumers living with impairment to navigate the marketplace. However, Beudaert et al. (2017) and Elms and Tinson (2012) highlight an ambiguity of coping strategies, whereby the offsetting of one marketplace barrier can result in the creation of another. For example, Elms and Tinson (2012) uncovered online shopping to help with offsetting physical marketplace barriers, yet they found this stimulated exclusion through a lack of social interaction in the marketplace. Meanwhile, Beudaert et al. (2017) highlight that small adaptations enacted by consumers with hidden auditory impairment often results in them being perceived as abnormal and impaired (i.e., wearing headphones or earmuffs to help with noise levels in shops being negatively viewed).

This paper agrees that coping strategies can be a source of ambiguity but extends this assertion to claim that coping strategies can further delimit and destabilise one's sense of self 
when living with impairment. The rationale for this claim lies in the discourse adopted by consumer research in this area to date. For example, Pavia and Mason $(2012,89)$ outline how consumers living with impairment see themselves as a "consumption challenge" in need of "negotiating" and "adaptation" (Mason and Pavia, 2006, 1024) to ensure they are a "good consumer that does not bring social transgression into the market" (Pavia and Mason, 2012, 107). Furthermore, findings from Echeverri and Salomonson $(2019,364)$ reveal how consumers living with impairment develop proactive and reactive coping strategies as a means of empowerment against experiences of vulnerability in marketplace settings. Skills such as implicit and explicit communication of their needs help them escape feeling de-humanised and commodified as objects by service providers. However, the fact they have learned to manage the service experience in this manner is a further sign of how they are socialised to believe it is they that need to adapt and change.

Baker et al. (2007) call for market actors to work against such vulnerability and oppressive forces yet, over a decade later, marketplace and market actors are not working to resolve vulnerability; rather, they are emplacing the responsibility upon the consumer to find systems and strategies to cope, negotiate and adapt to the marketplace. Such emplacement of responsibility further evidences a marketplace-orientated discursive power model (DenegriKnott et al., 2006, 960), whereby marketplace practices and services internalise external, dominant discourses of normative and conducive marketplace behaviour upon consumers living with impairment, instilling within them the belief that they are abnormal, unwelcome, at fault, and in need of adaptation to fit marketplace norms. Such placement of responsibility upon consumers living with impairment to adapt resonates with the concept of internalised oppression offered within the psycho-emotional model of disability (Reeve, 2002: 2004). 


\section{Psycho-Emotional Model of Disability}

Psycho-emotional disability is defined as a "form of social oppression involving the social imposition of restrictions of activity on people with impairments and the socially engendered undermining of their psycho-emotional wellbeing” (Thomas, 2007, 73). The work of Reeve (2002, 2004, 2012a, 2012b) has been pivotal from a psycho-emotional perspective. The psycho-emotional model believes limitations in societal structures as well as social interactions impose "barriers to doing" as well as "barriers to being" (Reeve, 2012a). Thus, Reeve does not view the psycho-emotional perspective as a replacement to the social model but, rather, an epistemological advancement that furthers understanding of the complex issues that surround impairment. In her model of psycho-emotional disability, Reeve (2004) offers three facets - structural barriers, social interaction and internalised oppression. Although not mutually exclusive, for the purpose of explication each are discussed separately.

Structural barriers, refers to how social and physical exclusion from particular environments can psychologically disable consumers living with impairment through them feeling unwelcome within particular public and private spaces. As aforementioned, marketplace exclusions can manifest through retail display height (Kaufman-Scarborough, 1999), lack of service training and precise online information on disability access (Navarro et al., 2014) as well as lighting and signage concerns (Yu et al. 2015). All are examples of how the marketplace, through certain structural barriers, can stimulate psycho-emotional disability for consumers living with impairment. In turn, this can heighten feelings of being "second class citizens" (Reeve, 2004, 86) reinforcing class distinctions between the disabled and able-bodied, and engulfing emotions of "inadequacy" (Bauman, 2005, 38) and negative psychological wellbeing upon consumers living with impairment.

Social interaction refers to how the dominance of ableism ensures that consumers living with impairment often experience taunts, are subjected to social gazes, and can be censured 
within society (Reeve, 2002). Reeve (2004) continues that social interaction can disempower those with impairment, resulting in them feeling like visitors in an able-bodied society, and creating feelings of shame, vulnerability and invalidation (Reeve, 2004). Echeverri and Salomonson's (2019) findings are reminiscent of such psycho-emotional disability. They outline how interactions between service provider, marketplace and consumer can have "negative implications for the consumer's sense of self-worth, integrity and capabilities" (2019, 18). In particular, their offering of the concept of commodification as a mode of vulnerability, whereby during marketplace interactions consumers living with impairment are objectified as objects over persons, resonates with the invalidating sense of self that can arise during social interactions.

Internalised oppression stems from the internalisation of the "prejudices and stereotypes held by the non-disabled majority" (Reeve, 2002, 496). Reeve (2002) perceives ableism to domineer consumers living with impairment, in turn affecting their sense of empowerment and self-value. For Reeve $(2004$, 89) internalised oppression is the most dangerous manifestation of psycho-emotional disability due to the "unconscious and insidious" effects it has upon psychological well-being, especially in directly restricting one's sense of self. Pavia and Mason's (2012) findings of parents of children with impairment developing escape plans, their advertence to being stigmatised as consumers who cause disturbances within marketplace settings, coupled with their discourse of perceiving their children and selves by being associated with impairment, as challenges in need of negotiation and adaptation to the market, are all indicative of marketplace-induced internalised oppression. Consequently, a psycho-emotional interpretation of this work evidences how coping and adaptations strategies have unconsciously yet oppressively internalised within consumers living with impairment, and those associated with them, the dominant assertion that deviation from consumer normalcy must be masked, hidden or removed (Baker, 2006). This paper, thus adopts the psycho- 
emotional model of disability as a lens of analysis, to extend consumer research discourse on disability by revealing how marketplace practices, interactions and services internally oppress and psycho-emotionally disable consumers living with impairment and, in doing so, entrench them within the dominant system of ableism.

\section{Methodology}

As aforementioned, the psycho-emotional model of disability offers insight into deeply personal and emotional experiences. To communicate in-depth such personal experience this paper draws from the interview data of a broader interpretive research study investigating access barriers to marketplaces for consumers living with impairment. This broader study included i) respondent observation through the shadowing, observation and, at times, physical caring for consumers living with impairment, ii) researcher introspection, iii) ad-hoc, in-situ fieldwork interviews, and iv) in-depth interviews with both verbal and non-verbal consumers living with impairment and/or their family members/carers. Together, these different approaches immersed the researcher fully within the research context helping to build holistic understanding of the lived realities of impairment. In particular, the active caring role undertaken by the researcher was not only instrumental in gaining such holistic understanding, but also greatly informed the in-depth interview process and paved the way for the undertaking of non-verbal interviews. It is outside the scope of this paper to discuss in totality the methodological approaches undertaken, nonetheless to help contextualise the interview process some insight is provided into the caring role undertaken by the researcher.

Throughout 2016-2017, the researcher travelled as a voluntary carer with a charity that permitted safe holidaying for consumers living with impairment. The researcher undertook two weeklong trips with the charity, both times being the sole, full-time carer for consumers with high-level needs that often times impaired their ability to walk, talk, feed, bathe and dress 
themselves. Prior to the trips, the researcher received care training from the charity. This provided basic training on how to safely move, feed, dress, shower, toilet and care for those travelling on the trip, as well as how to use specialist equipment such as hoists, wheelchairs, eye-tracking equipment, etc. However, no two people or impairments are the same; therefore, the researcher had to build a rapport and find a rhythm of how to safely, comfortably and respectfully lift, shower, toilet, dress, care and communicate with those she cared for.

In cases of non-verbalism (i.e. being unable to verbally speak), learning to communicate involved hand gestures, yes-no questioning and eye tracking via a letter-board, through which each word was spelt. Faced with no other means of communication, the researcher quickly learned how to listen "with all [their] senses, not just [their] eyes" (ForberPratt, 2019, 5), adapting to interpret self-directed actions, gestures, eye movements (particularly in using letter boards), utterances, expressions, etc. In this way a strong communication rhythm was developed, which permitted the planning and execution of nonverbal in-depth interviews, which, likewise, involved hand gestures and eye-spelling, but also utilised specialist computer systems, which often permitted respondents to type using their feet. Non-verbal interviews were often long in duration, to allow respondent's time to reflect on questions and then type. During fieldwork, the researcher had observed the energy it took respondents to communicate; consequently, non-verbal interviews often took place over multiple days and normatively included several breaks as a means of addressing fatigue and energy levels (Ashby, 2011).

Overall, in-depth semi-structured interviews were undertaken with 14 respondents (see Table 1.0). These included a mixture of consumers all living with physical impairment, their family members and/or carers, and lasted between 2-4 hours. Some interviews were undertaken separately, whilst others were undertaken in groups and, as discussed above, some were undertaken non-verbally (i.e. Tess and Kayleigh). Interview themes were not assigned a priori; 
rather, they emerged to allow respondents to guide the interview but, generally, discussion revolved around access barriers in marketplaces such as shops, transportation and tourism. Full ethical approval was granted and the researcher was overt at all times, regarding their research position. All respondents provided informed consent and are anonymised to ensure confidentiality. Interviews were all audio-recorded and later transcribed verbatim, amounting to over 500 pages, double-spaced. Fieldwork culminated in over 50 single-spaced pages of field-notes, 500 visuals and over two hours of ad-hoc interviews. Data was analysed using an iterative mode of analysis, with back and forth evaluations undertaken between theory, fieldwork and interview data (Spiggle, 1994). For example, early interviews found respondents sharing highly personal, psychological and emotional experiences, leading to the inclusion of this theme within the interview guide and resulting in the psycho-emotional interpretation shared in this paper. Member checking was conducted with all respondents to ensure the interpretation shared in this work is representative of respondents' own personal emotions and experiences. 
Table 1.0: Respondent Profiles

\begin{tabular}{|c|c|c|c|c|}
\hline $\begin{array}{l}\text { Respondent } \\
\text { Pseudonym }\end{array}$ & Age & Status & Impairment & Occupation (s) \\
\hline Anna & $50+$ & Impaired & $\begin{array}{l}\text { Non-diagnosed condition } \\
\text { causing extensive fatigue } \\
\text { levels. Began mid- } \\
\text { twenties. }\end{array}$ & Academic \\
\hline Tess & $50+$ & Impaired & $\begin{array}{l}\text { Athetoid Cerebral Palsy/ } \\
\text { non-verbal. }\end{array}$ & Artist and writer \\
\hline Bethany & $40+$ & $\begin{array}{l}\text { Carer for } \\
\text { terminally ill } \\
\text { husband }\end{array}$ & $\begin{array}{l}\text { Progressive supranuclear } \\
\text { palsy. }\end{array}$ & Tutor \\
\hline Tina & $40+$ & $\begin{array}{l}\text { Carer for } \\
\text { daughter }\end{array}$ & $\begin{array}{l}\text { Daughter has Warburg } \\
\text { Micro Syndrome. }\end{array}$ & $\begin{array}{l}\text { Product designer, charity } \\
\text { founder and trustee }\end{array}$ \\
\hline Chris & $40+$ & $\begin{array}{l}\text { Carer for } \\
\text { daughter }\end{array}$ & $\begin{array}{l}\text { Daughter has Warburg } \\
\text { Micro Syndrome. }\end{array}$ & $\begin{array}{l}\text { Businessman, } \\
\text { charity founder and trustee }\end{array}$ \\
\hline Hannah & $40+$ & $\begin{array}{l}\text { Carer for } \\
\text { daughter }\end{array}$ & $\begin{array}{l}\text { Daughter has Cerebral } \\
\text { Palsy. }\end{array}$ & Not-disclosed \\
\hline Kayleigh & $30+$ & Impaired & Cerebral Palsy/non-verbal. & Unemployed \\
\hline Martin & $60+$ & $\begin{array}{l}\text { Carer for } \\
\text { daughter } \\
\text { Kayleigh }\end{array}$ & $\begin{array}{l}\text { Daughter has Cerebral } \\
\text { Palsy. }\end{array}$ & Retired \\
\hline Mary & $60+$ & $\begin{array}{l}\text { Carer for } \\
\text { daughter } \\
\text { Kayleigh }\end{array}$ & $\begin{array}{l}\text { Daughter has Cerebral } \\
\text { Palsy. }\end{array}$ & Retired \\
\hline Miles & $50+$ & Impaired & $\begin{array}{l}\text { Non-disclosed. Shared it to } \\
\text { be a high level and } \\
\text { progressive condition. } \\
\text { Began mid-twenties. }\end{array}$ & $\begin{array}{l}\text { Business executive, charity } \\
\text { founder and trustee }\end{array}$ \\
\hline Kevin & $50+$ & Impaired & $\begin{array}{l}\text { Mobility-impaired } \\
\text { following stroke }\end{array}$ & Unemployed \\
\hline Kate & $50+$ & $\begin{array}{l}\text { Carer for } \\
\text { husband Kevin } \\
\text { and her } 20- \\
\text { year-old son }\end{array}$ & $\begin{array}{l}\text { Husband mobility impaired } \\
\text { following stroke. Son } \\
\text { quadriplegic following car } \\
\text { accident. }\end{array}$ & Hairdresser \\
\hline Matthew & $60+$ & Impaired & $\begin{array}{l}\text { Mobility-impaired } \\
\text { following stroke. }\end{array}$ & Unemployed \\
\hline Eleanor & $50+$ & $\begin{array}{l}\text { Carer for } \\
\text { husband } \\
\text { Matthew }\end{array}$ & $\begin{array}{l}\text { Husband mobility-impaired } \\
\text { following stroke. }\end{array}$ & Not disclosed \\
\hline
\end{tabular}




\section{Findings}

In adopting the psycho-emotional model of disability as a lens of analysis this paper extends consumer research by offering insight into how the marketplace internally oppresses and subsequently psychologically disables consumers living with impairment. Structured around Reeve's (2004) psycho-emotional model of disability, findings relate to the themes of structural barriers, social interaction and internalised oppression. As previously mentioned these facets are not mutually exclusive, but for the purpose of explication are discussed separately. Firstly, it is revealed how structural barriers and social interaction in marketplace settings disempower consumers living with impairment. Whilst, findings centring on internalised oppression unearth emergently the role the emotion of fear plays in psychoemotionally disabling consumers living with impairment and those associated with them. Table 2.0 further illustrates instances of marketplace induced internalised oppression and psychoemotional disability.

Table 2.0: Table of Data

\begin{tabular}{|c|c|c|}
\hline Structural Barriers & Social Interaction & Internalised Oppression \\
\hline $\begin{array}{l}\text { "I go down to London on the train } \\
\text { reasonably regularly for work. So } \\
\text { you're there to go and do your job } \\
\text { but they're [station staff] waiting } \\
\text { for everyone else to come off until } \\
\text { they come with the ramp to get } \\
\text { you. Because obviously to them } \\
\text { you're just having a bit of a day } \\
\text { trip - a jolly, you know? And } \\
\text { there is nothing you can do about } \\
\text { that - you're at their liberty" } \\
\text { (Anna). }\end{array}$ & $\begin{array}{l}\text { Martin: ... The looks at times from } \\
\text { non-disabled when you take their } \\
\text { luggage space, which is our } \\
\text { rightfully pre-booked seating space } \\
\text { - they are looks to kill. } \\
\text { INT: How do you deal with such } \\
\text { looks? } \\
\text { Martin: You cannot do anything, } \\
\text { you're powerless, you just have to } \\
\text { ignore it. }\end{array}$ & $\begin{array}{l}\text { "I'd be exhausted before I even got } \\
\text { to the train station. I'd be } \\
\text { absolutely worrying myself sick } \\
\text { that we'd get back alright, that's } \\
\text { what worries me now. Even if you } \\
\text { get to where you're going, I'm } \\
\text { worried about getting back. } \\
\text { If we're going to go anywhere, then } \\
\text { I have to control the situation so I } \\
\text { know we can get back. That means } \\
\text { I can't let my hair down, I can't } \\
\text { have a drink, I can't do anything, so } \\
\text { you're back to square one, "Let's } \\
\text { stay in and watch Coronation Street } \\
\text { [TV show]"' (Kate). }\end{array}$ \\
\hline
\end{tabular}




\begin{tabular}{|c|c|c|}
\hline $\begin{array}{l}\text { "We explained all the limitations, } \\
\text { the wheelchair and everything, } \\
\text { and when we get there, yes, you } \\
\text { could get a wheelchair in but } \\
\text { that's it, and you can't go through } \\
\text { beds, so we ended up having to } \\
\text { take furniture out. Wheelchair } \\
\text { accessible to them [service } \\
\text { provider] means getting in the } \\
\text { room and then you should be able } \\
\text { to walk, but I had explained that } \\
\text { he couldn't and was assured it } \\
\text { would be okay and it wasn't. } \\
\text { That's really put me off going } \\
\text { anywhere now" (Kate). }\end{array}$ & $\begin{array}{l}\text { "I know there's a really quick } \\
\text { turnaround for planes but they need } \\
\text { to factor in time allowance and not } \\
\text { board us last. Because when they } \\
\text { board us last and it takes a while for } \\
\text { us to board then the plane is } \\
\text { delayed. Then we have to ignore } \\
\text { and be polite when hearing the } \\
\text { huffs, puffs and snide comments } \\
\text { from other passengers and that's } \\
\text { not fair because it's not our fault- } \\
\text { we did not ask to be boarded last" } \\
\text { (Hannah). }\end{array}$ & $\begin{array}{l}\text { "In this pub that we go to quite } \\
\text { often, there was this early } 20 \text {-year- } \\
\text { old who didn't want to go at the } \\
\text { end of the table because it would be } \\
\text { near Penny [her daughter with } \\
\text { impairment]. I heard that, but not } \\
\text { well enough to be able to have gone } \\
\text { up to that person and have said } \\
\text { "that's not okay", but I hear stuff } \\
\text { like that all the time and I just have } \\
\text { to ignore it - it's easier to ignore it" } \\
\text { (Tina). }\end{array}$ \\
\hline
\end{tabular}

Structural Barriers: "You take my wheelchair from me, it's like taking my legs"

Behaviours such as forcing people with impairment to use separate entrances or sit in certain areas are forms of psycho-emotional disability created through structural barriers (Reeve, 2004). These can have inhibiting effects upon both consumers living with impairment, and those associated with them. This study found such behaviours to be evident across the marketplace, as illustrated by Anna regarding her experiences of air travel:

"So, if you can't walk onto the plane yourself you have in effect got to be carried onto the plane, which is fair enough. They strap you in to a small airplane wheelchair, and then they carry you on. That's fine, that helps you into your seat and yeah, there's a bit of manhandling, and then you're in your seat and that's okay. The problem is, this is part of people's work and I think they forget that they're dealing with people. So, you've got somebody who's checking people off and they've obviously got somebody who is a wheelchair user and they're calling 
up and down “carry-on, we've got carry-on”. And you're there thinking "hello, it's me, I'm an actual person" (Anna).

Anna's vignette outlines the separated manner in which she needs to board the plane, which often involves "manhandling". Nonetheless, she accepts that this is necessary if she wishes to travel. Her issue is not the structural barrier preventing her from independently accessing the airplane via her own wheelchair but, rather, how a lack of service training sees her perceived as airplane cargo by service employees. Labelled as cargo, Anna is seen as an object rather than a person, resonating with Echeverri and Salomonson's $(2019,374)$ discussion of commodification, whereby consumers living with impairment are often "treated as an object, rather than a human being". Such objectification denies Anna her sense of humanness and uniqueness, in turn thrusting her into a status of de-humanisation (Hill et al. 2016). Marks (1999) notes such experiences can create "epistemic invalidation". Such invalidation resonates with internalised oppression, whereby consumers living with impairment internalise the negative opinions and actions of ableism, believing themselves unworthy in, and to, society. This is witnessed in the manner in which Anna merely thinks, "it's me, I'm an actual person". Her reflection upon, rather than active challenging of, such behaviour outlines how being objectified as an inanimate object jeopardizes her sense of self-worth and psycho-emotionally disables her from challenging the dominant forces of ableism (Hutchinson et al, 2018).

Respondents shared their annoyance at being "controlled by" and "at the mercy of" service providers. Indeed, for Miles, such control at the hands of service providers saw his wheelchair offloaded from a plane: 
"I was travelling by plane and they weren't happy with loading my electric wheelchair. The steward just didn't have the knowledge. I told him, "it is an airline-approved battery. I can show you the paperwork." He said, "No, I don't believe that. I'm offloading it." I thought, "Really?" Because you see, you take my wheelchair from me, it is like taking my legs from me. But you come across people all around the world that should have had the training, but just don't know how to deal with these situations" (Miles).

Through his electric wheelchair, Miles is able to live independently; as such, his impairment raises complications but does not fully disable him. However, in this instance the lack of staff training not only physically but also psycho-emotionally disables him. As Miles shares, taking his chair is akin to taking his "legs", thus removing his independent sense of self. Miles's experience outlines the paradox of the wheelchair, whereby it can be a "vehicle of freedom of mobility and independence" (Papadimitriou, 2008. 701), that can both "form" and "transform" a person to communicate their true sense of self (Winance, 2006, 67). Yet, simultaneously, being the overarching symbol of disability signals wheelchair users as incapable, de-valued and governed over by dominant ableism (Guffey, 2018), illustrated clearly in the service provider's off-loading of Miles's chair despite having correct documentation.

Many respondents pointed towards the false promises of service providers as particularly frustrating, as evidenced by Bethany:

"Going to Spain was a nightmare. I checked with the travel agent and they assured us they would help us from the bus into the hotel. However, when we got to the hotel the coach stopped at the end of a long driveway and left us there - 
apparently, that was to the door service. Then the tour rep got off the bus and walked up the drive and into the hotel and left me. It was a no-win situation. I knew I couldn't leave my baby girl of three months and two-year old son at the bottom of the hill, but equally I hated that I would need to leave Peter [her husband], wheelchair bound and at that point close to quadriplegic there. Then afterwards I had to leave the children with complete strangers in the hotel. I felt really let down, but you don't want to go and ask for help or complain at that point, because you're exhausted. People don't always keep their promises but when you're travelling with somebody who has a disability you need them to keep them - you're relying on them. We should never have gone, it was not worth the stress, instead of creating happy family memories all I remember is the stress" (Bethany).

Bethany's attempt to create family memories with her children and terminally ill husband became a "nightmare" when the service promised was not provided. Respondents echoed Bethany's sentiments that service providers need to be honest and not over-promise. Overpromising can place consumers living with impairment, and those with them, into a state of disorientation when service providers are not considerate of their spatial and physical needs (Echeverri and Salomonson, 2019). Kennedy and Laczniak (2016) note that loss of trust in marketers, especially when they hold the power in marketer-consumer relationships, leads to greater scepticism. Such scepticism is magnified in the context of impairment where control is often further imbalanced towards marketers. For example, many family members, like Bethany and Kate (see Table 2), who are carers, highlighted such scepticism, sharing feelings of "uncertainty", "lack of trust" and "lack of control". Consequently, this study notes a point of departure from Reeve's (2004) work, which privileges the psycho-emotional experiences of 
those diagnosed with impairment, demonstrating instead how people not diagnosed but exposed to impairment through care and kinship can equally experience psycho-emotional disability. For example, in trying to care for but equally create special moments and times with their spouses both Bethany and Kate suffer, at the hands of structural barriers, a lack of control and sense of disempowerment thrusting them, likewise, into a state of psycho-emotional disability. This extends our understanding of psycho-emotional disability to account for not only consumers living with impairment but also those associated with them.

Social Interaction: "I have one just like that at home"

The marketplace was uncovered, at times, to subject consumers living with impairment or those associated with them to derogatory behaviours or reactions, further propelling them towards psycho-emotional disability. During fieldwork, the researcher encountered, and with permission audio-recorded an informal conversation with Diane, a young mother whose child has high impairment needs and is marked by a prominent facial growth. Diane shared that:

“On a weekly basis in supermarkets, shopping malls and on public transport, I am asked 'have you beaten your child up?' And constantly we have to endure people walking across the road, leaving shops, leaving lifts, moving tables in restaurants as though we are contagious... it's left me no longer wanting to go out in order to protect not only my daughter, but also myself because I honestly can't take it anymore" (Diane). 
The societal reception experienced by Diane and her daughter reveals that when impairment is highly visible dominant society often perceives those with impairment "as public property" (Morris, 1991, 29) and can react with "censure and disdain at a very primal level" (Pavia and Mason, 2012, 106). Reeve $(2018,59)$ asserts feelings of disgust and avoidance to be central to ableism, for "the body produced by ableism is clean and hygienic, contained and invulnerable, autonomous and independent - free from contamination or reminders of mortality and decay". Consequently, the behaviours enacted upon Diane and her daughter illustrate an interpersonal power relationship whereby, due to the regime of ableism, the dominant, able-bodied cohort feels more powerful and entitled to disempower persons with impairment whom they deem to be in "their" space (Reeve, 2004, 86). Norms would teach us that it is inappropriate to ask such insulting questions and enact such behaviours. Yet, under ableism, these norms are suspended as Tess clearly outlines:

\footnotetext{
"Back in 1992, we went on holiday to Scotland. My friend Debbie organised a day out to Highland Games. There were loads of tents with crafts and things. Debbie, my helper Vicki and I were in a craft tent and all of a sudden, a woman came up to us and said "I have one just like that at home!" and pointed straight at me. The woman then wandered away, unaware of the offence she could have caused. Vicki, Debbie and I burst out in fits of laughter at this random comment" (Tess).
}

The psycho-emotional effects of social interaction are believed to leave consumers living with impairment feeling “ashamed, vulnerable and invalidated" (Reeve, 2004, 87). Tess's laughter at the "random comment" could be interpreted as rising above this instance of invalidation. 
However, her reflection on this event, more than twenty years later, highlights the subtle ways in which social interactions can leave an enduring presence. When asked about the Highland Games and the crafts she bought, Tess could not recall any memories, replying "you know I don't know what I bought, if I bought anything or what we watched or saw - I just remember that woman". Rude comments, stares and behaviours from able-bodied persons was shared as not only frustrating, but also "mortifying" and "embarrassing", leading many respondents to wish they could "disappear" from social view:

"We had reserved seats, but then our train was cancelled so we had to board another train and that meant we didn't have seats. Therefore, the train manager asked people to give up their seats, which they agreed to, but then they stared at us the whole journey angrily. We just couldn't make eye contact with anybody at that point - we just wanted to disappear - never again will we train it" (Hannah).

Hannah outlines how although not her family's fault, fellow consumers misdirect blame upon them rather than service providers, causing them to experience psycho-emotional feelings of embarrassment and vulnerability. For many respondents this was a great annoyance, with them questioning why they should have to "endure" and "accept" the blame for service provider inadequacy:

"Where I see the negativity, is when I have had issues loading on the aeroplane, because of cock-ups by the airport team. And then other consumers have started to point the finger and huff and puff at me. That's when you see the negative of it, which is pretty horrible when it happens" (Miles). 
The "huffs and puffs" towards Miles, coupled with the angry stares towards Hannah and her family, are examples of "paralinguistic respirations" (Echeverri and Salomonson, 2019), that demonstrate fellow passengers' frustration and displeasure at consumers living with impairment (Table 2 offers further examples). It is arguable that all in society are subject to such respirations. However, the fact they are a direct response to impairment is what creates psycho-emotional disability, making those involved want to "disappear". However, as Miles explains, oftentimes this displeasure is misdirected, with the delay originating from "cock-ups" at the hands of service providers, not through the fault of the consumer living with impairment.

Pavia and Mason $(2012,109)$ outline parents of children with impairment to oftentimes find the "staring" and "whispering" of the public "so exhausting that parents may opt for exclusion". This paper further supports this, with all respondents sharing the psycho-emotional impact of public actions and, in particular, wrongful blame as "emotionally draining", making them feel "unwelcomed" by both service providers and fellow consumers. Yet, unlike the work from Echeverri and Salomonson (2019), this paper does not find consumers living with impairment adopt empowering coping strategies to deal with such behaviour. Contrarily, most respondents ignore and do not react to blameful and rude public behaviours, and often feel the need or desire to disengage from commercial settings. For example, Diane does not challenge people who disrespect her daughter and her when asking and enacting rude questions and behaviours. Yet, such public reaction has left her feeling emotionally vulnerable to the point of "no longer wanting to go out" and unable to "take it anymore". Similarly, Miles does not challenge the steward who inappropriately removes his wheelchair; rather, similar to Anna when referred to as cargo, he reflects on the behaviour inwardly. Once again, this signals epistemic invalidation and indicates how consumers living with impairment are internally oppressed and psycho-emotionally disabled by the dominant system of ableism. Shankar et al. 
(2006) argue that more product and service choice enables greater consumer empowerment. However, here, we see that consumers living with impairment do have a choice to consume services - the marketplace is available to them and apparently inclusive. Yet, service inadequacies continue to reinforce ableism within consumer culture, further plunging not only consumers living with impairment but also those associated with them into a state of disempowerment, internally oppressing and psycho-emotionally disabling them.

Internalised Oppression: "She is not as cute and acceptable as she perhaps was"

Reeve $(2004,88)$ defines internalised oppression as occurring when individuals accept, internalise and believe that in having an impairment they are "not full members of society". Respondents' aforementioned lack of resistance or challenge to rude public behaviour and questions is indicative of internalised oppression. Reeve (2002) also asserts that consumers living with impairment are not passive but have emancipatory tendencies and will fight and resist their labelling and treatment. Yet, as previously discussed consumers in this study showed no signs of emancipatory behaviour. Rather, an emergent finding of this study was the emotion of fear, with many respondents sharing their personal experiences of challenging social norms and bad service to result in "censure", "disdain" and "hatred", leaving them reluctant and fearful to resist such behaviour and service again. For example, Matthew shared that his complaints about medical treatment resulted in him being labelled as "one of those patients". Whilst, Tess shared that upon complaining about a full-time carer "the care levels got even worse, and oftentimes she [the carer] would return over an hour late from her lunch break, so I was just stuck there in my chair, stranded". Similarly, many respondents' experiences of resistance only further disempowered them, leaving many of them fearful for their own care needs or the needs of those they care for: 
"One of the nurses who was feeding Penny [tube-fed through her stomach] burnt all around her tummy. We complained about it and, then, at the next year's tubefeeding party, Penny wasn't invited. They no longer answered any out-of-hours calls or their pager. So, it has an impact. It's just easier not to do that again [complain]. But that needs to be pointed out as well, that kind of impact, for you make yourself invisible by just shutting out the reactions and actions around you" (Chris).

Reeve (2002) outlines psycho-emotional disability as commonly manifesting through feelings of shame, anger, frustration, and internalised oppression. However, this study, uncovers that fear also plays a critical role in psycho-emotional disability. As Chris highlights, his experience of complaining resulted in his daughter been excluded from social events and, more crucially, affected her care needs. Therefore, experience has taught him that is it "easier" not to complain for fear of possible repercussions. Similarly, as shown in Table 2.0, scepticism and fear of the unknown stops Kate and her husband from engaging with the marketplace, choosing instead to stay at home where she knows they are both safe. Together, these findings illustrate how fear is perpetuated by structural barriers and social interactions and, worryingly, can lead to cases of internalised oppression. Furthermore, Bethany, Kate and Chris's experiences all demonstrate how the inhibiting nature of the marketplace can internalise fear within not only consumers living with impairment, but also those associated with them, at times enforcing them to disengage entirely and/or avoid challenging service failures. Yet, as Chris powerfully explains, "shutting out the reactions and actions around you" and not challenging bad service only continues to hide the issues facing consumers living with impairment from public notice and, therefore, perpetuates ableism. 
Tina similarly outlines her personal fears for her daughter as she transitions from child to young adult:

"It is changing, because people used to really interact a lot more with Penny now she's becoming older and scarier to the public. I am worried about that, and I'm hoping she will carry on looking quite sweet and unthreatening. Things have definitely changed, the bigger she has gotten. She is not as cute and acceptable as she perhaps was. Obviously we don't care, but it's how many people approach us now, compared to when she was two, three, in what looked like a buggy, and then a tiny wheelchair - not so many" (Tina).

Tina's fear that her daughter will become "scarier to the public" and perceived as abnormal and monstrous rather than the beautiful person that she is, resonates with the idea of "faceist idealization" (Kearney et al. 2019, 8-9), whereby one is more likely to be included in the marketplace due to having a characteristic that is within a power-privileged group. Children in often being perceived as vulnerable and needing protection are in turn emplaced within such power-privileged groups, which could explain why more people interacted with Penny as a small child. Tina's fear of her daughter advancing into adulthood and not being as "cute and acceptable as she perhaps was" uncovers the unconscious depths of ableism, as she has internalised a belief that Penny's difference in ability as well as appearance will lead to censure and exclusion. Furthermore, recall Tess's trip to the Highland Games, and how it is a family member or carer for someone with an impairment that makes the comment, "I have one just like that at home!" Once again, this illustrates the pervasiveness of ableism. It is not only socialised within those who are able but likewise, socialised within and internalised oppressively by both consumers living with impairment and those closely aligned with them. 


\section{Discussion}

In adopting the psycho-emotional model of disability as a lens of analysis, this paper extends consumer research on disability. As outlined earlier, a large body of consumer research concerning disability focusses upon the coping and adaptation strategies enacted by consumers living with impairment (i.e., Mason and Pavia, 2006; Pavia and Mason, 2012; Echeverri and Salomonson, 2019). This paper is supportive of this work and believes it has done a great deal to raise awareness of disability exclusion within the marketplace. Nevertheless, adopting a psycho-emotional perspective offers a renewed conceptual interpretation, revealing consumer research prioritising coping and adaption strategies to have unwittingly perpetuated the system of ableism. Consequently, a core contribution of this paper is the deeper insight it offers into how the marketplace internally oppresses, and subsequently psycho-emotionally disables consumers living with impairment. Further contributions of this paper are three-fold. Firstly, this paper unearths how the emotion of fear is central to manifestations of psycho-emotional disability. Secondly, the paper offers a broader understanding of the marketplace practices that internally oppress and subsequently psycho-emotionally disable consumers living with impairment, outlining core perpetrators to be service providers and fellow consumers. Finally, findings uncover how psycho-emotional disability can extend beyond the context of impairment. Each contribution will be discussed, offering insight into theoretical and practical implications, and future research avenues.

\section{Psycho-emotional disability and fear}

To date, consumer research has uncovered consumers living with impairment to experience feelings of de-humanisation, invisibility, abnormality, upset, embarrassment and 
frustration within marketplace settings (i.e., Baker, 2006; Mason and Pavia, 2006; Pavia and Mason, 2012; Beudaert et al., 2017; Echeverri and Salomonson, 2019). The findings from this paper complement such work, uncovering similar emotions. These feelings can cause consumers living with impairment and those associated with them, to suffer a diminished and invalidated sense of self, causing them to suffer "identity dissolutions" (Pavia and Mason, 2014). However, an emergent contribution of this paper is the insight provided on the emotion of fear in internally oppressing consumers living with impairment. Fear originated from false promises, assurances, rude behaviours and bad service encounters, resulting in scepticism, and a loss of trust in marketers, service providers and fellow consumers. The consequence of this is that many respondents felt inhibited, and hence excluded, from the marketplace. Fear is perpetuated by structural barriers, social interactions and, worryingly, can lead to cases of internalised oppression for not only consumers living with impairment but, also, those who care for them, enforcing them at times to disengage entirely and/or avoid challenging service failures. Theoretically, this marks a point of departure from current consumer research, where fear has been discussed tangentially and only in relation to one's medical impairment. For example, Beudaert et al. (2016) outline their participants fear medical deterioration, not marketplace practices.

Echeverri and Salomonson $(2019,367)$ assert that consumers living with impairment are not "passive recipients of the bad things that come their way" but, rather, challenge service providers and employees as a means of alleviating their sense of vulnerability. Similarly, Reeve (2002) argues that from power regimes stems resistance, believing consumers living with impairment have emancipatory tendencies. Contrarily, this paper reveals resistance in oftentimes being negatively received, leads not to emancipation but, rather, to deeper forms of disempowerment and the internalisation of fear. Through such fear we see not only the perpetual disempowerment of consumers living with impairment, but also the "insidious and 
unconscious" (Reeve, 2004, 89) inhibiting influence of internalised oppression. Their internalisation of fear leaves them reluctant to complain against or resist the disabling marketplace practices enacted upon them, and thus hide issues of disability from public notice, further entrenching consumers living with impairment, and those associated with them, within the system of ableism.

\section{Marketplace practices that emotionally disable}

Mason and Pavia (2006, 1017) outline consumers living with impairment feel frustrated, upset and unwelcome in the marketplace due to the "indifference" shown by service providers and fellow consumers during marketplace encounters. This paper exposes the endurance of this issue. The indifference shown by service providers by restricting access to services (i.e., the offloading of Miles's wheelchair), offering false promises and assurances (i.e., Bethany and Kate), and failing to perceive consumers living with impairment primarily as consumers and people (i.e., Anna's labelling as cargo), are indicative of disempowering practices enacted by service providers that can and often do psycho-emotionally disable consumers living with impairment. Such practices create emotions of objectification, invalidation and, as abovementioned, fear. Similarly, the indifference shown by fellow consumers through the enacting of rude stares, comments, questions and utterances stimulates emotions that further disenfranchise consumers living with impairment.

Individually, these actors psycho-emotionally disable consumers living with impairment. However, this paper uncovers a complex and disabling interplay between service providers and fellow consumers. Any instance of service delay or failure can be exasperating for consumers and/or lead them into a state of vulnerability (i.e., travel delays meaning loss in promotion or job). However, in the context of impairment such vulnerability can be enhanced, with fellow consumers often times misdirecting blame for service failure upon consumers 
living with impairment. This, in turn, psycho-emotionally disables consumers living with impairment and those associated with them, causing them to disengage further from particular marketplaces or services. Such insight is crucial to marketers and service providers because an understanding of how particular practices and actions create psycho-emotional disability within the marketplace will permit the removal and/or revising of such practices. Resultantly, this paper calls for a repositioning of responsibility upon the marketplace to adapt to meet the needs of consumers living with impairment and those associated with them, and the following section offers recommendations for such adaptation.

The paper's discovery of misdirected blame upon consumers living with impairment uncovers the need for service providers to institute practices that are proactive not reactive. For example, drawing influence from Hannah's experience of train travel cancellation, service providers should institute protocols whereby consumers needing assistance are automatically re-assigned a seat without the need to involve fellow passengers. Both Baker (2006) and Navarro et al. (2014) call for service providers and employees to undergo better training to help augment service experiences for consumers living with impairment. Although this paper concurs that greater service training is mandatory, its findings uncover the need for an overhaul of such training, to consider not merely physical and structural, but also psycho-emotional disability. This will help employees to better understand not only the structural, physical restrictions of impairment, but uncover how the language they use and the behaviours they enact can disempower consumers living with impairment and those associated with them. Mason and Pavia (2006, 1025) highlight how individuals living with or associated with impairment are often "an invisible consideration to product/service developers and designers", leading them to question, "how do consumers that are invisible, or voiceless, in the marketplace be seen or heard?" To ensure the voices of consumers living with impairment and those that care for them are represented, the marketplace needs their co-creative input in re-developing 
and overseeing disability awareness training, as a means of ensuring it both meets their needs and prioritises a person over impairment approach. Indeed, such co-creative input is needed, not only within marketplace practice, but also within research agendas. A limitation of this paper, and all consumer research to date on impairment and disability, is its failure to adopt a participant-led approach. Consequently, we as scholars need to design research that places the consumer living with impairment, and those associated with them, at the centre in co-designing and co-implementing the research process. Such revisions in marketplace and consumer research practice will not only ensure consumers living with impairment, and those associated with them, are better included and catered to, but will also help to challenge and begin to alleviate experiences of ableism permeating consumer society.

\section{Psycho-emotional disability beyond impairment}

This paper clearly evidences how those not diagnosed but associated with impairment, often through care and kinship, can endure psycho-emotional disability. Bethany, Kate, Tina and Chris's experiences are all illustrative of how carers also experience psycho-emotional disability. Reeve (2004) claims that carers can inadvertently oppress those they care for by disengaging and removing them from societal interactions. However, this study reinterprets this logic. Disengagement from marketplace settings and interactions enacted by carers can be interpreted as not necessarily instances of oppression upon those diagnosed with impairment but, rather, personal instances of carers themselves experiencing psycho-emotional disability. This paper reveals feelings of fear, anger, frustration and disempowerment to be likewise experienced by those intimately associated with impairment, equally reducing their own senses of value, worth and self. Pavia and Mason (2014) outline that family members and those associated with impairment can suffer secondary degrees of vulnerability. However, their use 
of the word secondary is suggestive that the vulnerability level is somewhat lesser. This paper argues that the psycho-emotional disability experienced by carers is not lesser or secondary; rather, it is as powerful as that experienced by those diagnosed with impairment.

This finding marks a point of departure from work discussing psycho-emotional disability which, to date, has prioritised the impaired (i.e., Thomas, 1999, 2007; Reeve's, 2002, 2004, 2012a, 2012b) and, thus, raises a complex question - does one need to be impaired to be disabled? Indeed, as discussed earlier, disability is a socio-cultural construct that linguistically and symbolically has been established not by those who have impairment but by the ablebodied, therefore perpetuating ableism (Imrie, 1997, Shakespeare, 2004). Similar to us all being prone to vulnerability (Baker et al., 2005), neither are we immune from inability. Certainly, Shakespeare $(2004,19-20)$ outlines that we are all "impaired, to varying extents and at different times", whilst Galvin (2005) asserts the western compulsion of independence to be mythical, for in reality, we all rely on others. As such, this paper argues that the psychoemotional model of disability can be extended beyond the context of impairment, and be a useful lens for unpacking how the marketplace psycho-emotionally disables all consumers, within both marginalised and normative contexts. Such a perspective would help to divorce disability socio-culturally and discursively from impairment and, in turn, begin to normalise impairment and challenge the system of ableism.

For instance, the psycho-emotional model of disability could be fruitful in extending insight into the areas of consumer vulnerability and transformative consumer research. Consumer research has shown how gay pride festivals foster a sense of community and resistance against the stigma of homosexuality (Kates, 2003). Yet, such events are often subject to hate crimes (The Independent, 2019). The psycho-emotional model of disability has potential to unpack the emotional effects of this on individuals and the larger LGBTQ+ community. Similarly, Baker et al. (2005) outline that we are all susceptible to consumer 
vulnerability; as such, it is possible that in this consumer-cultural era of hyper-choice, a psychoemotional perspective could uncover psycho-emotional disability to be experienced by all consumers at certain points in time. Furthermore, although this study's focus on consumer research prioritises the perspective of consumers living with impairment and those associated with them, service providers may likewise be susceptible to psycho-emotional disability. For example, how do service providers feel when they are unable to adequately meet the needs of consumers with (and without) impairment due to lack of training, policy regulations and/or physical barriers? Consequently, future research could contribute to discourse on transformative services research by adopting a psycho-emotional perspective, aiming to understand how service encounters psycho-emotionally disable service providers as well as consumers both within the context of impairment and beyond. Finally, the UK perspective of this study is somewhat limiting; indeed, a criticism of the psycho-emotional model of disability is its UK-centric focus (Reeve, 2012b). Consequently, future research should look at how the psycho-emotional model of disability can be usefully applied in cultures beyond the UK.

\section{Conclusion}

In adopting the psycho-emotional model of disability, this paper contributes to and extends consumer research on disability, offering insight into the marketplace practices, interactions and services that internally oppress and psycho-emotionally disable consumers living with impairment. Further contributions offered by this paper: i) unearth the emotion of fear to be central to manifestations of psycho-emotional disability, ii) reveal a broader understanding of the marketplace practices, and core perpetrators, that psycho-emotionally disable consumers living with impairment, and iii) uncover psycho-emotional disability to extend beyond the context of impairment. Resultantly, this paper calls for a repositioning of responsibility upon 
the marketplace to adapt to meet the needs of consumers living with impairment, and those associated with them, as a means of beginning to challenge the dominant system of ableism currently permeating consumer culture.

This paper is not naïve in thinking such systemic change will occur rapidly, indeed Reeve (2012b) asserts psycho-emotional disability is harder to eradicate than structural disability. Nonetheless, Pavia and Mason $(2014,475)$ assert it is marketers' and marketing scholars' responsibility to: i) foster new systems that provide as "full an experience of the market as possible", ii) protect and support not only those diagnosed with impairment but the supporting ensemble that care for them, and iii) challenge broader systems that create vulnerability for consumers living with impairment. In bringing the psycho-emotional model of disability to consumer research, this paper begins to meet Pavia and Mason's (2014) call, and asks future consumer research to follow suit and conduct research that likewise challenges psycho-emotional disability and the current permeating system of ableism. After all, psychoemotional disability is not an individual, personal issue but, rather, a public issue created by "the ableism endemic in our society" (Reeve, 2012b, 91), and it is time that the marketplace, and we as marketing scholars, amend this.

\section{References}

Ashby, C. (2011). “Whose Voice is it Anyway?”: Giving Voice and Qualitative Research involving Individual that type to Communicate, Disability Studies Quarterly, Vol. 31(4), pp. $1-19$.

Baker, S.M. (2006). Consumer Normalcy: Understanding the value of shopping through narratives of consumers with visual impairments, Journal of Retailing, Vol. 81 (1), pp. 37-50. 
Baker, S.M., Stephens, D.L. and Hill, RP. (2001). How Can Retailers Enhance Accessibility: Giving Consumers with Visual Impairments a Voice in the Marketplace, Journal of Retailing and Consumer Services, Vol. 9, pp. 227-239.

Baker, S.M., Stephens, D.L., Hill, R.P. (2002). How can retailers enhance accessibility: giving consumers with visual impairments a voice in the marketplace, Journal of Retailing and Consumer Services, Vol. 9 (1), pp. 227-239.

Baker, S.M., Gentry, J.W., Rittenburg, T.L. (2005). Building Understanding of the Domain of Consumer Vulnerability, Journal of Macromarketing, Vol. 25 (2), pp. 128-139.

Baker, S.M., Holland, J., Kaufman-Scarborough,C. (2007). How consumers with disabilities perceive "welcome" in retail servicescapes: a critical incident study, Journal of Services Marketing, Vol. 21(3), pp. 160-173.

Bauman, Z. (2005). Work, Consumerism and the New Poor, Maidenhead: Open University Press.

Beudeart, A. (2018). Towards and embodied understanding of consumers with disabilities: Insights from the field of disability studies, Consumption, Markets and Culture, DOI: 10.1080/10253866.2018.1534734.

Beudaert, A. Ozcaglar-Toulouse, N., Ture M. (2016). Becoming sensory disabled: exploring selftransformation through rites of passage, Journal of Business Research, Vol. 69 (1), pp. 57-64.

Beudaert, A., Gorge, H., Herbert, H. (2017). An exploration of servicescapes' exclusion and coping strategies of consumers with "hidden" auditory disorders, Journal of Services Marketing, Vol. 31 (4/5), pp. 326-338.

Chouinard, V. (1997), Making Space for Disabling Differences: Challenging Ableist Geographies," Environment and Planning D: Society and Space, Vol. 15 (4), 379-387.

Denegri-Knott, J., Zwick, D., Schroeder, J. (2006). Mapping consumer power: an integrative framework for marketing and consumer research, European Journal of Marketing, Vol. 40 (9/10), pp. 950-971. 
Echeverri, P., Salomonson, N., (2019). Consumer Vulnerability during mobility service interactions: causes, forms and coping, Journal of Marketing Management, vol. 35 (3/4), pp. 364-389.

Elms, J. and Tinson, J. (2012). Consumer vulnerability and the transformative potential of internet shopping: an exploratory case study, Journal of Marketing Management, Vol. 28 (11/12), pp. $1354-1376$.

European Commission (2020). https://ec.europa.eu/social/main.jsp?catId=1137 - last accessed 26.02.20.

Forber-Pratt, A.J. (2019). Musings from the streets of India: Voice for the disabled who are nonverbal, Qualitative Inquiry, DOI: 10.1177/1077800419846635.

Galvin, R.D. (2005). Researching the disabled identity: Contextualising the identity transformations which accompany the onset of impairment, Sociology of Health and Illness, Vol. 27 93), pp. 393-413.

Goodley, D. (2017). Disability Studies: An Interdisciplinary Introduction, Sage, London, $2^{\text {nd }}$ Edition.

Guffey, E. (2018). Designing Disability: Symbols, Space and Society, London: Bloomsbury. Hill, R.P., Cunningham, D., \& The Gramercy Gentlemen. (2016). Dehumanization and Restriction inside a Maximum Security Prison: Novel Insights about Consumer Acquisition and Ownership, Journal of the Association for Consumer Research, Vol. 1 (2), pp. 357-364.

Hutchinson, K. Roberts, C., Daly, M. (2018). Identity, impairment and disablement: Exploring the social processes impacting identity change in adults living with acquired neurological impairments, Disability and Society, Vol. 33 (2), pp. 175-196.

Imrie, R. (1997). Rethinking the relationships between disability, rehabilitation and society, Disability and Rehabilitation, Vol. 19 (7), pp. 263-271. 
Kates, S.M. (2003). Producing and Consuming Gendered Representations: An Interpretation of the Sydney Gay and Lesbian Mardi Gras, Consumption, Markets and Culture, Vol. 6 (1), pp. 522.

Kaufman-Scarborough, C. (1995). Shop 'til you drop: Tales from a Physically Challenged Shopper. Journal of Consumer Marketing, Vo. 12 93), pp. 39-55.

Kaufman-Scarborough, C. (1999). Reasonable Access for Mobility-Disabled Persons is More Than Widening the Door, Journal of Retailing, Vol. 75 (4), pp. 479-508.

Kaufman-Scarborough, C. (2001). Sharing the experience of mobility-disabled consumers: Building understanding through the use of ethnographic research methods, Journal of Contemporary Ethnography, Vol. 30 (4), pp. 430-464.

Kaufman-Scarborough, C. (2015). Social Exclusion: A perspective of consumers with disabilities, in K. Hamilton, S. Dunnett and M. Piacentini (eds), Consumer Vulnerability: Conditions, Contexts and Characteristics, Routledge, Oxon, pp. 157-169.

Kearney, S., Brittain, I., Kipnis, E. (2019). "Superdisabilities" vs “disabilities”? Theorizing the role of ableism in (mis)representational mythology of disability in the marketplace, Consumption, Markets and Culture, DOI: 10.1080/10253866.2018.1562701

Kennedy, A.M., Laczniak, G.R. (2016). Conceptualisations of the Consumer in Marketing, European Journal of Marketing, Vol. 50 (1/2), pp. 166-188.

Marks, D. (1999). Dimensions of Oppression: Theorizing the Embodied Subject, Disability and Society, Vol. 14 (5), pp. 611-626.

Mason, M.J. and Pavia, T.M. (2006). When the Family System Includes Disability: Adaptation in the Marketplace, Roles and Identity, Journal of Marketing Management, Vol. 22 (9-10), pp. 1009-1030.

Morris (1991). Pride against prejudice: Transforming attitudes to disability, London: Women's Press. 
Navarro, S., Andreu, L., Cervera, A. (2014). Value co-creation among hotels and disabled customers: An exploratory study, Journal of Business Research, Vol. 67 (1), pp. 813-818.

Oliver, M. (1990). The Politics of Disablement, Basingstoke, Macmillan.

Papadimitriou, C. (2008). Becoming en-wheeled: The situated accomplishment of re-embodiment as a wheelchair user after spinal cord injury, Disability and Society, Vol. 23 (7), pp. 691-704.

Pavia, T.M., Mason, M.J. (2012). Inclusion, exclusion and identity in the consumption of families living with childhood disability, Consumption, Markets and Culture, Vol. 15 (1), pp. 87-115.

Pavia, T.M., Mason, M.J. (2014). Vulnerability and Physical, Cognitive, and behavioral Impairment Model Extensions and Open Questions, Journal of Macromarketing, Vol. 34 (4), pp. $1-15$.

Purple: Changing the Conversation (2020). https://wearepurple.org.uk/the-purple-poundinfographic/ - last accessed 26.02.20.

Reeve, D. (2002). Negotiating Psycho-emotional Dimensions of Disability and their Influence on Identity Constructions, Disability and Society, Vol. 17 (5), pp. 493-508.

Reeve, D. (2004). Psycho-emotional dimensions of disability and the social model, in C. Barnes and G Mercer (eds) Implementing the Social Model of Disability: Theory and Research, Leeds: The Disability Press, pp.83-100.

Reeve, D. (2012a). Psycho-Emotional Disablism the lives of people experiencing mental distress, in J.Anderson, B. Sapey and H. Spandler (eds), Distress or Disability? Proceedings of a symposium held at Lancaster Disability 15-16 November 2011, Lancaster: Centre for Disability Research, Lancaster University, pp. 24-29.

Reeve, D. (2012b). Psycho-Emotional Disablism: The missing link?, in N. Watson, A. Roulstone and C. Thomas (eds) Routledge Handbook of Disability Studies, London: Routledge, pp. 7892. 
Reeve, D. (2018). Disgust and Self-Disgust: A Disability Studies Perspective, in P.A. Powell, P.G. Overton and J. Simpson (eds.), The Revolting Self: Perspectives on the Psychological, Social and Clinical Implications of Self-Direct Disgust, New York: Routledge, pp. 53-74.

Shakespeare, T. (2004). Social models of disability and other life strategies, Scandinavian Journal of Disability Research, Vol. 6 (1), pp. 8-21.

Shankar, A., Cherrier, H., Canniford, R. (2006). Consumer Empowerment: A Foucauldian Interpretation, European Journal of Marketing, Vol. 40 (9/10), pp. 1013-1030.

Snyder, S.L., Mitchell, D.T. (2001). Re-Engaging the Body: Disability Studies and the resistance to embodiment, Public Culture, Vo. 13 (3), pp. 367-389.

Spiggle, S. (1994). Analysis and Interpretation of Qualitative Data in Consumer Research, Journal of Consumer Research, Vol. 21 (3), pp. 491-503.

Swain, J., French, S. (2000). Towards an Affirmation model of Disability, Disability and Society, Vol. 15 (4), pp. 569-582.

The Independent (2019). https://www.independent.co.uk/news/uk/crime/muslim-woman-gaypride-parade-march-abuse-london-hate-crime-a9023996.html - last accessed 26.02.20.

Thomas, C. (1999). Disability and the Social Self, in C. Thomas (ed.), Female Forms: Experiencing and Understanding Disability, Buckingham: Open University Press, pp. 46-61.

Thomas, C. (2007). Sociologies of Disability, Impairment and Chronic Illness: Ideas in Disability Studies and Medical Sociology. London: Palgrave.

Trees, R. and Dean, D. (2018). Physical and emotional nourishment: Food as the embodied component of loving care of elderly family relatives, European Journal of Marketing, Vol. 52 (2), pp. 2405-2422.

United Nations Convention on the Rights of Persons with Disabilities (2006). https://www.un.org/disabilities/documents/convention/convoptprot-e.pdf - last accessed 26.02.20. 
Winance, M. (2006). Trying out the wheelchair: the mutual shaping of people and devices through adjustment, Science, Technology and Human Values, Vol. 31 (1), pp. 52-72.

Yu, H., Tullio-Pow, S., Akhtar, A. (2015). Retail design and the visually impaired: A needs assessment, Journal of Retailing and Consumer Services, Vol. 24 (1), pp. 121-129. 